\title{
Basis for the Hypoactivity that Accompanies Rapid Weight Gain in Hamsters
}

\author{
KATARINA T. BORER, CAREN D. POTTER AND NANNETTE FILECCIA \\ Department of Kinesiology, The University of Michigan \\ 401 Washtenaw Avenue, Ann Arbor, MI 48109
}

Received 20 August 1982

\begin{abstract}
BORER, K. T., C. D. POTTER AND N. FILECCIA. Basis for the hypoactivity that accompanies rapid weight gain in hamsters. PHYSIOL BEHAV 30(3) 389-397, 1983.-The pattern of hypoactivity that accompanies rapid weight gain following septal lesions in hamsters was characterized. Lesioned hamsters displayed reduced levels of running, shorter and slower running bouts, and longer pauses. We examined whether this hypoactivity was due to reassignment of metabolic fuels from supporting physical activity to anabolism, or due to reduced capacity of running to induce psychomotor arousal and mobilize metabolic fuels. Septal lesions were associated with increased rate of ponderal growth and higher titers of circulating growth hormone and insulin. No difference in concentrations of muscle and liver glycogen, percentage of body fat, or the capacity of muscle homogenates to oxidize substrates were identified. Lesioned hamsters ran as fast and as long as control animals on electrical-shock reinforced treadmill, but were unable to generate as much heat in response to injection $(0.8 \mathrm{mg} / \mathrm{kg})$ of norepinephrine. We conclude that hypoactivity that accompanies rapid weight gain in hamsters results either from a reduced capacity of running to induce psychomotor arousal and provide incentives that normally motivate that behavior, or from a failure of running to mobilize metabolic fuels at a rate necessary to sustain normal running speed and duration, and not from reduced availability of metabolic fuels or reduced muscle capacity to oxidize metabolic substrates.
\end{abstract}

Hypoactivity Weight gain Septal lesions Hamsters

BODY weight of animals and humans affects the level of spontaneous physical activity. In response to a weight loss, hamsters [3], rats [14,42], and kangaroo rats [17] increase their levels of voluntary running in a variety of rotating or spinning activity devices. Conversely, weight gain during growth-inducing exercise $[2,3]$ or as a result of growth- or obesity-inducing lesions of limbic forebrain and hypothalamus in hamsters $[7,8]$ and rats $[11,22,26,31,48,52]$ is correlated with reduced running on activity discs and wheels. Finally, increases in body fatness above the norm in hamsters [3], genetically obese rats and mice $[29,50,58]$ infants [46], adolescents $[12,30,49]$, and adult humans $[1,13]$ all are associated with reduced physical activity.

Thus, if one examines the relationship between the level of fatness, or the rate of weight change and the levels of spontaneous running activity, in hamsters, an inverse proportionality becomes apparent [3]. At the weight-loss end of the scale, animals jeopardize their energy balance and physical survival by increasing energy expenditure as their energy stores decline. Kangaroo rats will die [17] and underweight hamsters will become comatose and hypothermic [4] from high levels of running activity if they are exposed to activity devices in the absence of adequate supply of food. At the weight-gain end of the scale, progressive reduction in voluntary activity levels in animals and humans that are gaining weight may contribute to accumulations of excess energy reserves. Thus, rather than contribute to energy homeosta- sis, voluntary running appears to be nonhomeostatic and to contribute to energy imbalance. Underweight mammals aggravate this energy imbalance by increasing their levels of voluntary activity, and overweight mammals enhance their fat accumulation by becoming hypoactive.

The nonhomeostatic nature of this relationship has prompted us to investigate the basis for the hypoactivity that accompanies rapid weight gain induced by lesions of rostromedial septum [5]. We tested two hypotheses. The first hypothesis, that hypoactivity results from endocrine and metabolic reassignment of metabolic fuels from supporting physical activity to anabolic processes, as suggested by experiments of Eng et al. [19] was tested in the following ways. We measured concentrations of serum insulin and growth hormone because of their roles in the control of anabolism and fuel mobilization and storage. We measured quantities of two metabolic fuels that support prolonged physical activities, muscle and liver glycogen and body fat to see whether they differ in hypoactive and control animals. We measured the rate of exidation of metabolic substrates by quadriceps muscle homogenates, and the capacity to run at different speeds and durations on motor driven treadmill to determine whether hypoactive hamsters have reduced capacity to mobilize metabolic fuels. Treadmill experiments also served to rule out damage to motor nervous system as a cause of reduced levels of running.

The second hypothesis that hypoactivity results from re- 
duced capacity of running to induce psychomotor arousal and mobilization of metabolic fuels was tested in the following ways. We determined that the characteristics of running pattern in hypoactive hamsters consists of reduced speed and duration of running bouts and increased duration of pauses. We introduced electric foot shock in the treadmill experiments to see whether this hypoactivity resulted from the reduced capacity of running to induce psychomotor arousal and provide incentives that normally motivate this behavior. We compared general physical activity and voluntary running activity in lesioned and control animals to see whether rapid weight gain is accompanied by reduction in all types of general movement, or is specific for motivated behaviors requiring higher levels of energy expenditure, such as voluntary running. We measured energy expenditure induced by an injection of norepinephrine to see whether hypoactive hamsters show a reduced capacity to undergo sympathetic arousal that accompanies physical activity.

\section{METHOD}

\section{Animals and Maintenance}

Adult golden female hamsters, Mesocricetus auratus Waterhouse, were obtained from Engle Laboratory Animals, Farmersburg, IN at the age of ten weeks and at body weights in excess of $90 \mathrm{~g}$. Animals were maintained in temperature $\left(21-22^{\circ} \mathrm{C}\right)$ and light-controlled (12L:12D) rooms with unlimited access to water and Purina 5008 Formulab chow pellets. 12L:12D Photoperiod appears to be photostimulatory in female hamsters. Females continue to display estrous cyclicity, breed [3], and have high concentrations of circulating prolactin characteristic of long-day photoperiodic exposure [6]. While sedentary, animals were housed in standard suspended rodent cages with wire bottoms.

\section{Measurements of Physical Activity and Energy Expenditure}

To induce voluntary running, hamsters were housed in acrylic boxes ( $30 \mathrm{~cm}$ wide, $40 \mathrm{~cm}$ long, and $32 \mathrm{~cm}$ high) with wire bottoms and a permanently mounted horizontal disc exerciser, 23 to $25 \mathrm{~cm}$ in diameter. Disc turns were recorded as revolutions per day (RPD) on electromechanical counters activated by microswitch closures. A Harvard cumulative event recorder with paper speed of $5 \mathrm{~cm} / \mathrm{min}$ and eventactivated sideway pen excursion ( $1 \mathrm{~mm} / 4$ events) allowed computation of total activity in RPDs, the number and duration of running bouts and pauses, and running speed during a running bout in revolutions per minute (RPM). A running episode was defined as $\mathbf{2 0}$ disc revolutions or more flanked by inactive periods of 150 seconds or longer, and pauses, as inactive periods of at least 150 seconds.

To measure levels of general physical activity, hamsters were housed in acrylic boxes with wire bottoms $(29 \mathrm{~cm}$ wide, $39 \mathrm{~cm}$ long, and $32 \mathrm{~cm}$ high) which had three pairs of infrared photoelectric sensors (New Standard Systems, Cincinnati, $\mathrm{OH}$ ) mounted $4.5 \mathrm{~cm}$ above the floor along the cage width at $10 \mathrm{~cm}$ intervals. To measure energy expenditure by indirect calorimetry hamsters were placed in a cylindrical chamber $15 \mathrm{~cm}$ long and $10 \mathrm{~cm}$ in diameter. Room air was forced through the chamber at a flow rate of about one liter per minute. Determinations of oxygen concentration in dehydrated samples of air before and after passage through the animal chamber were made with an S-3A oxygen meter (Applied Electrochemistry, Sunnyvale, CA). Determinations of heat production were made: during one hour of daytime, with food and water present and with animal generally resting; during one half hour following an IP injection of norepinephrine $(0.8 \mathrm{mg} / \mathrm{kg})[24]$ and immediately following the baseline oxygen consumption determination

\section{Growth Inducing Lesions}

Rapid somatic growth unaccompanied by obesity, was induced in hamsters by lesions of rostromedial septum [5]. With skull surface horizontal between lambda and bregma, coordinates were, $5 \mathrm{~mm}$ ventral from the dura and $2 \mathrm{~mm}$ anterior to bregma at the midline. Two $\mathrm{mA}$ of direct current was delivered for $20 \mathrm{sec}$ through the uninsulated tip of the stainless-steel electrode. Control operations involved the same procedure except that the electrode was lowered $3 \mathrm{~mm}$ below the dura and no current was administered. At the close of testing, hamsters were sacrificed, their brains were fixed in $10 \%$ buffered formalin and alternate $80 \mu \mathrm{m}$ coronal sections were stained with cresyl violet to determine the extent and location of damage.

\section{Measurements of Somatic Growth}

Somatic growth was measured in two ways. Ponderal growth rate was obtained from the least-squares linear regression of weight change as a function of time. Determinations of body fatness [28] also provided further information on the nature of lesion-induced weight increases.

\section{Determinations of Concentrations of Metabolic Fuels}

Concentration of glycogen in muscle and liver were determined by the procedure of Good et al. [23]. Percentage of body fat was determined by the procedure of Horwitz [28].

Determination of Oxidative Capacity of Muscle Homogenates

The capacity of the quadriceps muscle homogenate to oxidize malate and pyruvate substrates was determined by procedure of Hooker and Baldwin [27].

\section{Hormone Determinations}

Blood for hormone determinations was collected in chilled glass tubes following decapitation between the second and the third hour after the onset of light and allowed to clot. Blood collection at the same time of day served to minimize the contribution of ultradian rhythms of hormone release to data variability [10]. Serum was stored at $-20^{\circ} \mathrm{C}$ for determinations of growth hormone and insulin concentrations. Growth hormone was measured with a homologous radioimmunoassay for hamster growth hormone [10]. Insulin determinations were made with a double antibody radioimmunoassay using an antibody against porcine insulin developed in a guinea pig, labeled procine insulin and a purified rat insulin standard (Eli Lilly Research Laboratories). Assay sensitivity was $13 \pm 3$ pg per tube and interassay coefficient of variation for a standard hamster serum was $15.7 \%$.

\section{Determinations of Running Power and Endurance}

Determinations of the ability of hamsters to run at different speeds and to run for prolonged periods of time were made during the period of darkness using a shock-reinforced motor-driven treadmill (Quinton Instruments Co., Seattle, WA, Model 42-15). In tests of running power, animals ran for two minutes at speeds which ranged from $0.5 \mathrm{~km} / \mathrm{hr}$ (the 
preferred running speed of lesioned hamsters) to $2 \mathrm{~km} / \mathrm{hr}$ (just above the preferred running speed of control hamsters) with the treadmill at a $15 \%$ incline. Two minute rest periods separated individual speed tests. The ability of the animal to keep pace with the running belt was noted five times during the two minute speed test and scored as proportion of the two minutes that the animals remained on the belt. In endurance running tests, hamsters ran on the treadmill at $1 \%$ incline at $0.64 \mathrm{~km} / \mathrm{hr}$ for a brief period of acclimatization. The speed was then progressively increased to $1 \mathrm{~km} / \mathrm{hr}$ for the next hour, to $1.28 \mathrm{~km} / \mathrm{hr}$ for the following 20 -minute period, and by $0.32 \mathrm{~km} / \mathrm{hr}$ for each subsequent 20 -minute period. Hamsters were kept running until exhaustion which was defined as loss or righting reflex.

Calculations [37] of the amount of work on the treadmill were based on the relationship $W=F \times D$, where $W$ stands for work, F stands for force (i.e., animals's weight) and D represents distance that animal raises itself in walking up the incline. D was further determined from the relationship $\mathrm{D}=($ sine $\theta) \times d$ where $\mathrm{d}$ stands for distance traveled along the incline and was derived from $d=V \cdot T$. V stands for speed of running, and $\mathrm{T}$ for time spent running. Running power was derived from the relationship $\mathrm{P}=\mathrm{W} / \mathrm{T}$ [37].

\section{Data Analysis}

All data are expressed as means and standard errors of the means. Data were analyzed by two-tailed Student's $t$-tests, Mann Whitney $U$ tests and $2 \times 2$ analysis of variance. Power and endurance data were evaluated using a profile analysis of the slopes.

Due to nonhomogeneous distribution of hormone values, statistical analyses were performed on logarithmic transformations of the data.

Experiment 1: Amount and Pattern of Voluntary Running Activity and Amount of General Locomotor Activity Following Growth-Inducing Septal Lesions

The objective of Experiment 1 was to characterize changes in locomotor activity that accompany septal-lesion induced acceleration of growth. To that end, quantity and pattern of voluntary running on activity discs were measured as a reflection of goal-directed motivated behavior, and the quantity of general locomotor activity on the cage floor was measured as a reflection of general undirected state of arousal of the animal. It was of interest to determine whether septal lesions induced generalized hypoactivity, or affected one of these motor systems selectively.

Animals and procedures. Nine lesioned and eight control animals as described were exposed to activity discs during $\mathbf{2 0}$ days beginning with the second postoperative day. Ten lesioned and 14 control animals remained sedentary. Growth was determined during postoperative days two through 19. Total running activity was measured in nine septal-lesioned and eight control hamsters between postoperative days 2 and 22. Running patterns were determined in six of the nine lesioned and six of the eight control hamsters during a 24 hour period occurring on postoperative days 10 to 18 with random assignments within conditions. Running speeds were converted from RPM to $\mathrm{km} / \mathrm{hr}$ assuming functional running diameters ranging between 12 and $18 \mathrm{~cm}$ on a $25-\mathrm{cm}$ activity disc [2]. General activity was determined in a separate group of six lesioned and six control hamsters between postoperative days 2 and 14.
Experiment 2: Availability of Metabolic Fuels for Voluntary Running Activity

The objective of Experiment 2 was to determine whether there was a difference in the concentration of the two hormones, insulin and growth hormone, and in the amounts of muscle and liver glycogen and in the fat stores between lesioned and control hamsters that could account for differences in their levels of voluntary activity.

Animals and procedures. Twenty-one septal lesioned and twenty-one control hamsters were used for determination of muscle and liver glycogen. Thirteen animals in each group were killed on postoperative day 20 , and the remainder on postoperative day 45 . Seven septal lesioned and seven control animals killed on day 20 , and all of the animals killed on day 45 , were used for body fat determinations.

Experiment 3: Power and Endurance Capacities of SeptalLesioned and Control-Operated Hamsters on Shock Reinforced Motor Driven Treadmill

The purpose of Experiment 3 was to determine whether septal-lesioned hamsters could run as fast and as long as control operated hamsters when motivated by electric foot shock delivered any time animals failed to keep pace with the running belt.

Animals and procedures. Ten septal-lesioned and ten control-operated hamsters were exposed to a speed-ofrunning test on postoperative day 36 , to endurance test on postoperative days 43 and 50 , and to three days of voluntary disc activity between postoperative days 51 and 52 . Results were expressed in units of time, in units of work, or in units of power necessary to perform the work, respectively. Conversion to work or power units was necessary to correct for variation in the amounts of work imposed by differences in body weight between septal-lesioned and control animals, particularly in the endurance test in which animals' weights and length of running at individual speeds contributed to significant variation in total energy output.

\section{Experiment 4: Capacity of Muscles to Utilize Metabolic Substrates in Septal-Lesioned and Control Hamsters}

The purpose of this experiment was to determine whether rapid growth, induced by septal lesions, was associated with reduced capacity of muscles to oxidize metabolic fuels for exercise.

Animals and procedures. Quadriceps muscle from animals in Experiment 3 were used for measurements of oxidative capacity.

\section{Experiment 5: Norepinephrine-Induced Thermogenic Capacity in Septal-Lesioned and Control Hamsters}

The purpose of this experiment was to determine whether septal lesions reduced hamster's capacity for sympathetic activation of heat production.

Animals and procedures. One hour determination of resting metabolic rate was made during the light period immediately followed by a 30 minute determination of oxygen consumption in response to an injection of norepinephrine $(0.8 \mathrm{mg} / \mathrm{kg})$ during postoperative days $7-14$ in six lesioned and six control hamsters. 
TABLE 1

CHANGES IN PONDERAL GROWTH RATE, IN THE AMOUNT AND PATTERN OF VOLUNTARY RUNNING ACTIVITY AND IN GENERAL LOCOMOTOR ACTIVITY IN SEPTAL-LESIONED AND CONTROL-OPERATED HAMSTERS

\begin{tabular}{|c|c|c|c|c|c|}
\hline & \multicolumn{2}{|c|}{ Septal-lesioned } & \multicolumn{2}{|c|}{ Control } & \multirow{2}{*}{$\begin{array}{l}\text { Significance } \\
\qquad(p)\end{array}$} \\
\hline & Exercising & Sedentary & Exercising & Sedentary & \\
\hline $\begin{array}{l}\text { Ponderal growth rate } \\
\text { (g/day) }\end{array}$ & $1.6 \pm 0.1^{*}$ & $1.9 \pm 0.2$ & $1.2 \pm 0.2$ & $0.4 \pm 0.1$ & $\begin{array}{l}0.01 \mathrm{~S} \\
0.01 \mathrm{SxE}\end{array}$ \\
\hline Activity Level (RPD) & $5,130 \pm 1779$ & & $28,406 \pm 2206$ & & 0.001 \\
\hline $\begin{array}{l}\text { Duration of running } \\
\text { bouts (min) }\end{array}$ & $18.9 \pm 6.2$ & & $56.0 \pm 10.3$ & & 0.02 \\
\hline $\begin{array}{l}\text { Total pause time } \\
\text { (min) }\end{array}$ & $50.0 \pm 16.5$ & & $9.2 \pm 1.8$ & & 0.05 \\
\hline Running speed (RPM) & $17.9 \pm 3.7$ & & $47.8 \pm 2.4$ & & 0.001 \\
\hline $\begin{array}{l}\text { Number of running } \\
\text { bouts }\end{array}$ & $10.8 \pm 3.0$ & & $11.0 \pm 1.7$ & & N.S. \\
\hline $\begin{array}{l}\text { General locomotor } \\
\text { activity (number of } \\
\text { photobeam breaks) }\end{array}$ & $24,990 \pm 2678$ & & $17,242 \pm 4844$ & & N.S. \\
\hline
\end{tabular}

${ }^{*}$ Mean \pm SEM

$S=$ effect of septal lesion.

$\mathrm{S} \times \mathrm{E}=$ effect of interaction between septal lesion and exercise.

\section{RESULTS}

Experiment 1: Amount and Pattern of Voluntary Running Activity and of General Locomotor Activity Following Growth-Inducing Septal Lesions

Septal lesions led to significant increase in the rate of ponderal growth as did exercise in neurologically-intact hamsters (Table 1). In addition, septal lesions induced significant reductions in the level of voluntary running activity (Table 1). Lesioned hamsters engaged in the same number of running bouts, but their running bouts were shorter, total pause time between their runs was longer and their running speed was lower than in control operated hamsters (Table 1). The preferred running speed of septal lesioned hamsters was between 0.4 and $0.6 \mathrm{~km} / \mathrm{hr}$ and of control operated hamsters between 1.2 and $1.9 \mathrm{~km} / \mathrm{hr}$. Although the septal lesions were associated with reduced levels and speed of voluntary dis running, deficit in this goal-directed motivated behavior was not accompanied by generalized hypoactivity. Instead, septal lesioned animals generated as many photobeam breaks on the cage floor as did the control-operated hamsters (Table 1).

\section{Experiment 2: Availability of Metabolic Fuels for Voluntary Running Activity}

Septal lesioned animals displayed significantly higher rates of ponderal growth, and had significantly higher concentrations of serum insulin and growth hormone. However, concentrations of metabolic fuels, i.e., muscle and liver glycogen and percentage of body fat, did not differ between lesioned and control operated animals (Table 2) despite the significant increases in body weight induced by lesions (to $136 \pm 3.4 \mathrm{~g}$ by day 20 , and $180.4 \pm 6.2 \mathrm{~g}$ by day 45 compared to corresponding weights of $114 . \pm 4.4 \mathrm{~g}$ and $115.1 \pm 6.2 \mathrm{~g}$ in sham operated hamsters, $p<0.001$ ).
Experiment 3: Power and Endurance Capacities of Septal Lesioned and Control Operated Hamsters on ShockReinforced, Motor-Driven Treadmill

As in Experiments 1 and 2, (also 5), septal lesions induced significant acceleration of ponderal growth. Between days 1 and 50, ponderal growth rate was $1.0 \pm 0.1$ in the lesioned animals and $0.3 \pm 0.01$ in the controls $(p<0.001)$. Capacity of lesioned and control hamsters to run on shock-reinforced treadmill at different speeds is illustrated in Fig. 1. Profile analysis of the length of time on the treadmill as well as of power necessary to run at different speeds, showed no impairment in the running capacity of lesioned hamsters as compared to controls.

Endurance capacity of lesioned hamsters did not differ from that of controls whether it was expressed in units of time, or after normalization for weight differences, in units of work or power (Table 3). However, lesioned animals engaged in significantly less voluntary running than control operated hamsters (Table 3 ).

\section{Experiment 4: Capacity of Muscles to Utilize Metabolic} Substrates in Septal-Lesioned and Control Hamsters

No difference was found in the oxidative capacity of quadriceps muscle between septal-lesioned (day 20: $1.75 \pm 0.3$, day $45: 1.55 \pm 0.3 \mathrm{ml} \mathrm{O}_{2} / \mathrm{g} / \mathrm{hr}$ ) and control hamsters (day 20: $1.42 \pm 0.2$, day $45: 1.97 \pm 0.3 \mathrm{ml} 0_{2} / \mathrm{g} / \mathrm{hr}$ ).

Experiment 5: Norepinephrine-Induced Thermogenic Capacity in Septal-Lesioned and Control Hamsters

Lesions accelerated ponderal growth from $0.5 \pm 0.1 \mathrm{~g} /$ day to $2.9 \pm 0.3 \mathrm{~g} /$ day $(p<0.001)$. Baseline heat production was similar in lesioned $\left(2.4 \pm 0.4 \mathrm{ml} 0_{2} / \mathrm{g} / \mathrm{hr}\right)$ and control-operated hamsters $\left(2.8 \pm 0.1 \mathrm{ml} 0_{2} / \mathrm{g} / \mathrm{hr}\right)$. However, septal-lesioned 
TABLE 2

PONDERAL GROWTH RATES, CONCENTRATIONS OF SERUM INSULIN AND GROWTH HORMONE, CONCENTRATIONS OF MUSCLE AND LIVER GLYCOGEN, AND BODY FATNESS IN SEPTAL-LESIONED AND CONTROL HAMSTERS KILLED ON POST-OPERATIVE DAYS 20 OR 45

\begin{tabular}{llccc}
\hline & & & Control & $\begin{array}{c}\text { Significance } \\
(p<)\end{array}$ \\
\hline Ponderal growth & day 20 & $2.5 \pm 0.2$ & $1.0 \pm 0.3$ & 0.01 \\
$\quad$ rate (g/day) & day 45 & $2.0 \pm 0.2$ & $0.6 \pm 0.2$ & 0.01 \\
Serum insulin & day 20 & $6.7 \pm 1.9$ & $0.6 \pm 0.6$ & N.S. \\
$\quad$ ng/ml) & day 45 & $17.3 \pm 6.1$ & $1.7 \pm 0.4$ & 0.01 \\
$\begin{array}{l}\text { Serum growth } \\
\text { hormone (ng/ml) }\end{array}$ & day 20 & $23.9 \pm 9.3$ & $6.7 \pm 1.9$ & 0.02 \\
$\begin{array}{l}\text { Muscle glycogen } \\
\text { (mg/g) }\end{array}$ & day 20 & $16.1 \pm 7.8$ & $21.2 \pm 8.5$ & N.S. \\
$\begin{array}{l}\text { Liver glycogen } \\
\text { (mg/g) }\end{array}$ & day 45 & $0.7 \pm 0.5$ & $1.2 \pm 0.6$ & N.S. \\
Body Fat (\%) & day 20 & $1.9 \pm 0.5$ & $1.2 \pm 0.6$ & N.S. \\
& day 20 & $11.0 \pm 2.1$ & $11.5 \pm 0.6$ & N.S. \\
& day 45 & $15.2 \pm 4.5$ & $13.3 \pm 3.3$ & N.S. \\
\hline
\end{tabular}

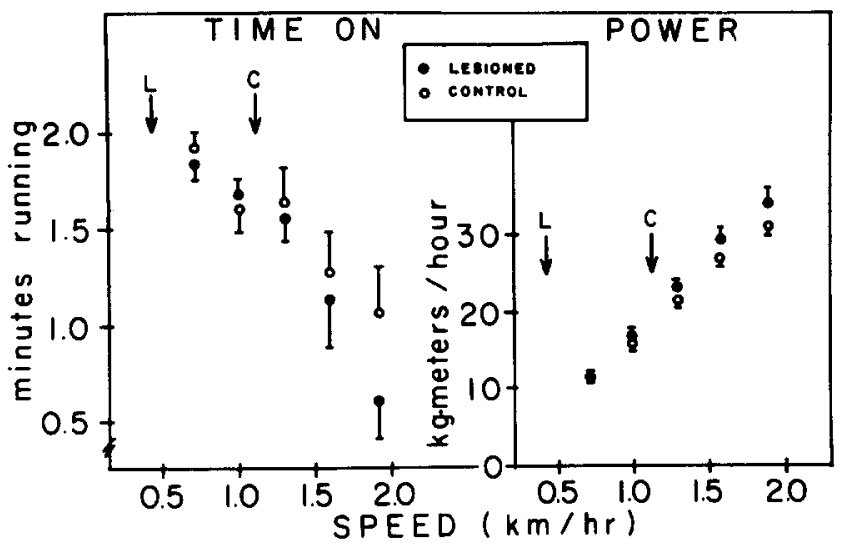

FIG. 1. Capacity of septal-lesioned (solid circles) and control hamsters (open circles) to run at different speeds on treadmill. Values are expressed in units of time animals remained on treadmill belt during two-minute test at different speeds (left) and in units of power necessary to keep pace with treadmill speed (right).

animals were significantly less responsive to the sympathetic activation of heat production. Their norepinephrine-induced metabolic rate was only $4.2 \pm 0.5 \mathrm{ml} 0_{2} / \mathrm{g} / \mathrm{hr}$ compared to $6.2 \pm 0.3 \mathrm{ml} 0_{2} / \mathrm{g} / \mathrm{hr}$ in control operated hamsters $(p<0.01)$.

\section{Location of Brain Damage and Correlation with Running Deficit}

To identify brain area most closely associated with hypoactivity and increased ponderal growth, histological damage was plotted for seven lesioned hamsters from experiments 1 and 3 whose postoperative running levels were less than 2,000 RPD and whose rate of weight gain was $1.1 \pm 0.2$ $\mathrm{g} /$ day. In this group of animals, damage was confined to rostromedial septum and extended about $1.5 \mathrm{~mm}$ anterior to the anterior commissure (Fig. 2).
To relate hypoactivity to lesion-induced anabolism we examined the correlation between these two variables in 17 septal-lesioned hamsters from Experiments 1 and 3 and in seven control hamsters from Experiment 3 that have been exposed to voluntary running for 3 days, a period of time that is too brief to accelerate somatic growth. In neurologically intact, slowly growing hamsters $(-0.01$ to $0.49 \mathrm{~g} /$ day $)$ there was a negative correlation between ponderal growth and activity level $\mathrm{y}=-0.0000009 \pm 0.28, p<0.001$ (Fig. 3). By contrast, in lesioned hamsters growing at rates between 0.49 and $2.32 \mathrm{~g} /$ day, there was a positive correlation between ponderal growth and activity level, $y=0.000293 x+1.1367$ $(p<0.01)$.

\section{DISCUSSION}

The purpose of this study was to determine the basis for the hypoactivity that accompanies rapid weight gain in hamsters with septal lesions.

We first ruled out the availability of metabolic fuels as the cause for septal-lesion-induced hypoactivity. Eng $e t$ al. [19] have hypothesized that hypoactivity in female rats which gain weight rapidly following cuts parasagittal to medial basal hypothalamus, was the result of oversecretion of insulin and of the supposed diminished availability of metabolic fuels for exercise. Although in our septal-lesion model, rapid anabolism is accompanied with significant increases in serum insulin and growth hormone concentrations (Table 2), high titers of anabolic hormones did not affect the amounts of metabolic fuels available for exercise (Table 2).

We have, furthermore, found no differences between lesioned and control hamsters in the ability of muscle homogenates to oxidize malate and pyruvate (Experiment 4). Long-duration, moderate-intensity exercise, such as is carried out each night by neurologically intact hamsters [2] depends on body fat as a metabolic fuel [3] and requires mitochondrial aerobic oxidation of this fuel. In the running hamster, the use of body fat as metabolic fuel is evident from continuous reductions in body fatness in spite of rapid body growth, throughout the four weeks of exposure to running 


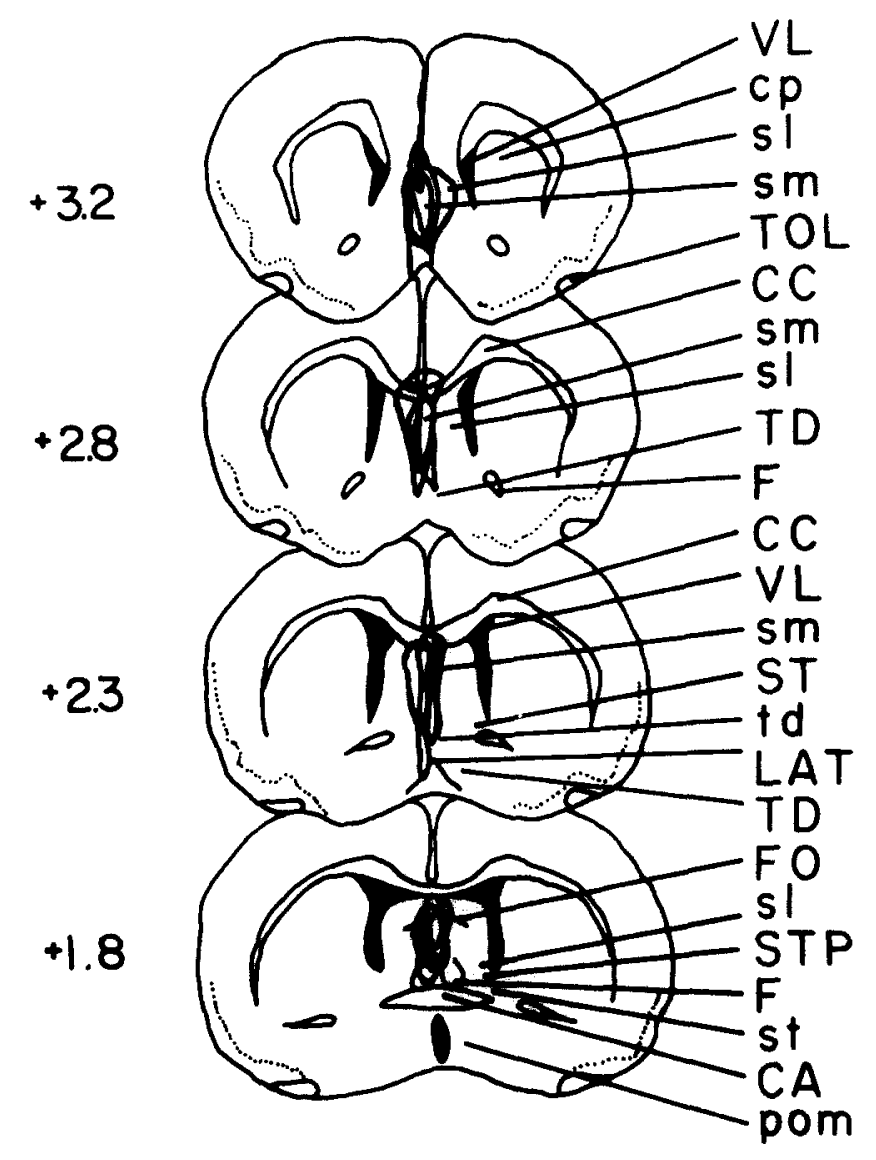

FIG. 2. Location of brain damage in seven septal-lesioned hamsters with running activity levels of less than 2,000 RPD.

\section{ABBREVIATIONS}

$\begin{array}{ll}\text { CA } & \text { anterior commissure } \\ \text { CC } & \text { corpus callosum } \\ \text { Cp } & \text { nucleus caudate putamen } \\ \text { F } & \text { columns of the fornix } \\ \text { FO } & \text { fornix } \\ \text { LAT } & \text { lamina terminalis } \\ \text { POM } & \text { medial preoptic nucleus } \\ \text { Sl } & \text { lateral septal nucleus } \\ \text { SM } & \text { medial septal nucleus } \\ \text { ST } & \text { stria terminalis } \\ \text { St } & \text { nucleus of the stria } \\ & \text { terminalis } \\ \text { TD } & \text { diagonal band of Broca } \\ \text { td } & \text { nucleus of the diagonal } \\ & \text { band } \\ \text { TOL } & \text { lateral olfactory tract } \\ \text { VL } & \text { lateral ventricle } \\ \text { VIII } & \text { third ventricle }\end{array}$

activity (Moffatt and Borer, unpublished data, 1981). Thus, septal lesions did not impair the aerobic oxidation of metabolic fuels.

To gain a better insight into the nature of hypoactivity that accompanies rapid weight gain, we determined that septal-lesion-induced hypoactivity is characterized by the normal number of running bouts, but by reduced duration of

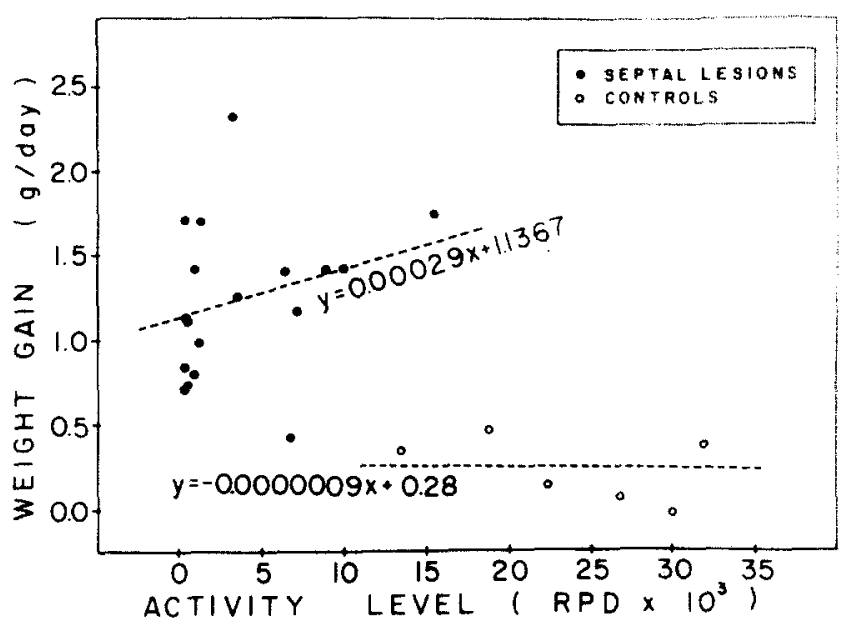

FIG. 3. Correlations between ponderal growth and activity levels in septal-lesioned hamsters (solid circles; $y=0.000293 x+1.1367$ ) and control operated-hamsters (open circles; $y=0.0000009 x+0.28$ ).

individual runs, reduced speed of running and increased duration of pauses between the runs (Table 1). On the other hand, septal-lesioned hamsters displayed normal levels of general locomotor activity (Table 1). This pattern of locomotor deficits suggested to us that hypoactivity on horizontal discs was not the outcome of general reduction in psychomotor arousal. Rather either a decreased motivation to engage in voluntary running, or decreased capacity of running to mobilize metabolic fuels was responsible for the observed hypoactivity on the running discs in hamsters with septal lesions.

The motivational interpretation was particularly strongly supported by our treadmill experiments in which we have demonstrated that septal-lesioned hamsters are capable of running as fast (Fig. 1) and as long (Table 3) as control hamsters if they are motivated by electric foot shock.

The motivational interpretation of the observed hypoactivity in septal-lesioned animals is consistent with the known involvement of cerebral catecholamines in incentive behaviors such as voluntary running and locomotion $[20,32,36$, $41,44,47,54,56)$ and intracranial self-stimulation $[15,16,21$, $25]$.

We assume that psychomotor arousal that accompanies voluntary running in hamsters requires normal concentrations of cerebral and hippocampal noradrenaline, because hamsters with rostromedial septal lesions (present experiment and [5]), hippocampal transections [7], and hypothalamic undercuts [8], all of which induce hypoactivity, are accompanied with significant depletion of hippocampal and cerebral-cortical norepinephrine [9]. Electric shock is known to facilitate the release of norepinephrine in hypothalamus, hippocampus, and cerebral cortex in rats $[33,39,43,53]$, the regions of the brain where catecholamines have been implicated in facilitation of locomotion and incentive behaviors in the rodents. Thus, shock-induced release of cerebral catecholamines could account for shock-induced normalization of running speed and endurance in septal-lesioned hamsters.

It is well known that heat production by the brown adipose tissue is activated by the sympathetic nervous sys- 
TABLE 3

\begin{tabular}{|c|c|c|c|}
\hline & Septal-lesioned & Control & $\begin{array}{c}\text { Significance } \\
(p<)\end{array}$ \\
\hline $\begin{array}{l}\text { ndurance time } \\
\text { (hr) }\end{array}$ & $1.7 \pm 0.2^{*}$ & $2.2 \pm 0.3$ & N.S. \\
\hline $\begin{array}{l}\text { indurance work } \\
(\mathrm{kg} \cdot \mathrm{m})\end{array}$ & $2.3 \pm 0.3$ & $3.3 \pm 0.4$ & N.S. \\
\hline $\begin{array}{l}\text { ndurance power } \\
(\mathrm{kg} \cdot \mathrm{m} / \mathrm{hr})\end{array}$ & $1.5 \pm 0.1$ & $1.4 \pm 0.04$ & N.S. \\
\hline activity level & $1376 \pm 711$ & $30381 \pm 4507$ & 0.001 \\
\hline
\end{tabular}

${ }^{*}$ Mean \pm SEM.

tem [24]. We have used a norepinephrine injection as a diagnostic test to see whether lesion-induced hypoactivity may be due to a reduced capacity of running to stimulate sympathetic activity. Our findings in Experiment 5 were opposite from those expected. In septal-lesioned hamsters, basal sympathetic activity, as reflected in basal metabolic rate, was normal, but peripheral response to experimentally administered sympathetic challenge was subnormal. Our tentative conclusion is that septal lesions influence target tissue responsiveness to sympathetic stimulation. Thus, reduced sympathetic output and deficient catecholamine metabolism in peripheral organs is present in hypoactive, genetically obese rodents $[34,35,40]$ and is associated with weight gains that results from damage to medial basal hypothalamus $[29,45]$ which are also accompanied by hypoactivity. Although Experiment 5 does not support the notion that septal lesions induce reduced sympathetic outflow and concomitant reduction in mobilization of metabolic fuels for prolonged and rapid running bouts on activity discs, it does suggest that septal lesions render target tissues less sensitive to the effects of catecholamines. Thus lesioned hamsters may be unable to sustain long and rapid running bouts when they engage in disc running because of subnormal responsiveness of muscle, glycogen and lipid stores to the calorigenic stimulation by catecholamines. Since electric shock induces sympathetic arousal and release of adrenal medullary catecholamines [51], it may correct lesion-induced hypoactivity by providing supranormal concentrations of catecholamines and thus by compensating for the reduced sensitivity of target tissues to this stimulus. This hypothesis needs to be put to a direct experimental test.

We believe that our experiments shed light on the biological function of the observed negative correlation between the energy content of the body and the level of voluntary activity in mammals $[3,14,17,42]$.

The disappearance of the negative correlation between these two variables in hypoactive rapidly growing animals (Fig. 3) indicates that its neural substrate was damaged by our lesions. The noradrenergic cortical and hippocampal circuits may thus mediate psychomotor and metabolic arousal under circumstances involving adaptive responses of animals toward their environment, such as search for food, search for mates, or escape from predators. Increases in locomotion in energy-depleted rodents indicate enhanced psychomotor arousal that may promote vigorous exploration of the environment for food. Along the same line, increased titers of sex hormones facilitate running behavior in rats [55], but not hamsters [3], and may facilitate encounter of mates and reproduction. Increased length of daylight promotes increased levels of running activity in hamsters [18,57], and this seasonal influence may thus facilitate exploration of the environment for food and mates as well as enhance ponderal growth $[2,3]$.

Running on activity devices is an artificial laboratory phenomenon, where activity devices with high reinforcing properties, allow us to study a brain circuit which ordinarily compels animals to make biologically sound but bioenergetically expensive locomotor responses.

\section{ACKNOWLEDGEMENTS}

This research was supported, in part, by the National Science Foundation grants PCM 78-07626 and PCM 81-04375 to Katarina T. Borer. We thank M. Root, Lilly Research Laboratories for the gift of purified rat insulin and $M$. Markovs for the gift of antiserum to porcine insulin.

\section{REFERENCES}

1. Bloom, W. L. and M. F. Eidex. Inactivity as a major factor in adult obesity. Metabolism 16: 679-684, 1967.

2. Borer, K. T. Characteristics of growth-inducing exercise. Physiol Behav 24: 713-720, 1980.

3. Borer, K. T. The nonhomeostatic motivation to run in the golden hamster. In: Changing Concepts of the Nervous System, edited by A. R. Morrison and P. L. Strick. New York: Academic Press, 1982, pp. 539-567.
4. Borer, K. T. and R. P. Kelch. Increased serum growth hormone and somatic growth in exercising adult hamsters. Am J Physiol 234: E611-E616, 1978.

5. Borer, K. T., R. P. Kelch, M. P. White, L. Dolson and L. R. Kuhns. The role of the septal area in the neuroendocrine control of growth in the adult golden hamster. Neuroendocrinology 23: 133-150, 1977. 
6. Borer, K. T., R. P. Kelch and K. Corley. Hamster prolactin: Physiological changes in serum and pituitary concentrations as determined by a homologous radioimmunossay. Neuroendocrinology 35: 13-21, 1982.

7. Borer, K. T., R. P. Kelch, J. Peugh and C. Huseman. Increased serum growth hormone and somatic growth in adult hamsters with hippocampal transections. Neuroendocrinology 29: 22-33, 1979.

8. Borer, K. T., N. L. Peters, R. P. Kelch, A. C. Tsai and S. Holder. Contribution of growth, fatness, and activity to weight disturbance following septohypothalamic cuts in adult hamsters. J Comp Physiol Psychol 93: 907-918, 1979.

9. Borer, K. T., M. E. Trulson and L. R. Kuhns. The role of limbic system in the control of hamster growth. Brain Res Bull 4: 239$247,1979$.

10. Borer, K. T., R. P. Kelch and T. Hayashida. Hamster growth hormone: Species specificity and physiological changes in blood and pituitary concentrations as measured by a homologous radioimmunoassay. Neuroendocrinology 35: 349-358, 1982.

11. Brooks, C. McC. The relative importance of changes in activity in the development of experimentally produced obesity in the rat. Am J Physiol 147: 708-716, 1946.

12. Bullen, B. A., R. B. Reed and J. Mayer. Physical activity of obese and non-obese adolescent girls appraised by motion picture sampling. Am J Clin Nutr 14: 211-223, 1964

13. Chirico, A. M. and A. J. Stunkard. Physical activity and human obesity. $N$ Engl J Med 263: 935-940, 1960.

14. Collier, G. H., E. Hirsch, D. Levitsky and A. I. Leshner. Effort as a dimension of spontaneous activity in rat. J Comp Physiol Psychol 88: 89-96, 1975.

15. Crow, T. Catecholamine containing neurons and electrical self-stimulation: 1. Review of some data. Psychol Med 2: 414 $421,1972$.

16. Crow, T. Catecholamine containing neurons and electrical self-stimulation: 2. A theoretical interpretation and some psychiatric implications. Psychol Med 3: 66-73, 1973.

17. Dill, D. B., L. F. Soholt and J. D. Morris, Jr. Wheel running of kangaroo rats, Dipodomys merriami, as related to food deprivation and body composition. J Appl Physiol 44: 17-20, 1978.

18. Ellis, G. T. and F. W. Turek. Changes in locomotor activity associated with the photoperiodic response of the testes in male golden hamsters. J Comp Physiol 132: 277-284, 1979.

19. Eng, R., R. M. Gold and P. E. Sawchenko. Hypothalamic hypoactivity prevented but not reversed by subdiaphragmatic vagotomy. Physiol Behav 20: 637-641, 1978.

20. Fink, J. S. and G. P. Smith. Mesolimbico-cortical dopamime terminal fields are necessary for normal locomotor and investigatory exploration in rats. Brain Res 99: 359-384, 1980.

21. German, D. C. and D. M. Bowden. Catecholamine systems as the neural substrate for intracranial self-stimulation: A hypothesis, Brain Res 74: 381-419, 1974.

22. Gladfelter, W. E. and J. R. Brobeck. Decreased spontaneous locomotor activity in the rat induced by hypothalamic lesions. Am J Physiol 203: 811-817, 1962.

23. Good, C. A., H. Kramer and M. Somogyi. The determination of glycogen. J Biol Chem 100: 485-491, 1933

24. Heldmaier, G., S. Steinlechner, J. Rafael and P. Usiansky. Photoperiodic control and effect of melatonin on nonshivering thermogenesis and brown adipose tissue. Science 212: 917-919, 1981

25. Herberg, L. J., D. N. Stephens and K. B. J. Franklin. Catecholamines and self-stimulation: Evidence suggesting a reinforcing role for nonadrenaline and a motivating role for dopamine. Pharmacol Biochem Behav 4: 575-582, 1976.

26. Hetherington, A. W. and S. W. Ranson. The spontaneous activity and food intake of rats with hypothalamic lesions. $A \mathrm{~m} \mathrm{~J}$ Physiol 136: 609-617, 1942.

27. Hooker, A. M. and K. M. Baldwin. Substrate oxidation specificity in different types of mammalian muscle. Am J Physiol 236: C66-C69, 1979.
28. Horwitz, W., editor. Meat and meat products, 24,005. Cructe tat or ether extract-official final action. In: Official Methods of Analysis of $A O A C, 11$ th edition. Washington, DC: American Organization of Analytical Chemists, 1970.

29. Inoue, S. and G. Bray. Role of the autonomic nervous system in the development of ventromedial hypothalamic obesity. Brain Res Bull 5: Suppl 4, 119-126, 1980.

30. Johnson, M. L., B. S. Burke and J. Mayer. Relative importance of inactivity and overweight in the energy balance of obese high school girls. Am J Clin Nutr 4: 37-44, 1956.

31. Kennedy, G. C. and J. Mitra. Hypothalamic control of energy balance and the reproductive cycle in the rat, $J$ Physiol 166: 395-407, 1963.

32. Koob, G. F., L. Stinus and M. LeMoal. Hyperactivity and hypoactivity produced by lesions to the mesolimbic dopamine system. Behav Brain Res 3: 341-359, 1981.

33. Korf, J., G. K. Aghajanian and R. H. Roth. Increased turnover of norepinephrine in the rat cerebral cortex during stress: Role of locus coeruleus. Neuroendocrinology 12: 933-938, 1973.

34. Levin, B. E., J. Triscari and A. C. Sullivan. Defective catechol amine metabolism in peripheral organs of genetically obese Zucker rats. Brain Res 224: 353-366, 1981.

35. Levin, B. E., J. Triscari and A. C. Sullivan. Abnormal sympatho-adrenal function and plasma catecholamines in obese Zucker rats. Pharmacol Biochem Behav 13: 107-113, 1982.

36. Mason, S. T. and H. C. Fibiger. Interaction between noradrenergic and cholinergic systems in rat brain: Behavioral function in locomotor activity. Neuroscience 4: 517-526, 1979.

37. Mathews, D. K. and E. L. Fox. The Physiological Basis of Physical Education and Athletics. Philadelphia: W. B. Saunders Co., 1976, pp. 64-65.

38. Mayer, J. Decreased activity and energy balance in the hereditary obesity-diabetes syndrome of mice. Science 117: 504-505, 1953.

39. Maynert, E. W. and R. Levi. Stress-induced release of brain norepinephrine and its inhibition by drugs. I Pharmacol Exp Ther 143: 90-95, 1964

40. Milam, K. M., J. S. Stern and B. A. Horwitz. Isoproterenol alters non-shivering thermogenesis in the Zucker obese rat. Pharmacol Biochem Behav 16: 627-630, 1982.

41. Mogenson, G. J., D. L. Jones and C. Y. Yim. From motivation to action: Functional interface between the limbic system and the motor system. Prog Neurobiol 14: 69-97, 1980.

42. Moskowitz, M. J. Running wheel activity in the white rat as a function of combined food and water deprivation. $J \mathrm{Comp}$ Physiol Psychol 52: 621-625, 1959.

43. Nakagawa, R., M. Tanaka, Y. Kohno, Y. Noda and N. Nagasaki. Regional responses of rat brain noradrenergic neurones to acute intense stress. Pharmacol Biochem Behav 14: 729-732, 1981.

44. Pijnenburg, A. J. J., W. M. M. Honig, J. A. M. Van Der Heyden and V. M. Van Rossum. Effect of chemical stimulation of the mesolimbic dopamine system upon locomotor activity. Eur $J$ Pharmacol 35: 49-58, 1976.

45. Powley, T. L. and W. Laughton. Neural pathways involved in hypothalamic integration of autonomic responses. Diabetologia 20: $378-387,1981$.

46. Rose, H. E. and J. Mayer. Activity, calorie intake, fat storage and the energy balance of infants. Pediatrics 41: 18-29, 1968

47. Schlosberg, A. J. and J. A. Harvey. Effect of L-DOPA and L-5 hydroxytryptophan on locomotor activity of the rat after selective or combined destruction of central catecholamines and serotonin neurons. I Pharmacol Exp Ther 211: 296-304, 1979.

48. Sclafani, A. Neural pathways involved in the ventromedial hypothalamic lesion syndrome in the rat. J Comp Physiol Psychol 77: $70-76,1971$

49. Stefanik, P. A., F. P. Heald, Jr and J, Mayer. Caloric intake in relation to energy output of nonobese and obese adolescent boys. Am J Clin Nutr 7: 55-62, 1959.

50. Stern, J. S. and P. R. Johnson. Spontaneous activity and adipose cellularity in the genetically obese Zucker rat (fafa) Metabolism 26: 371-380, 1977. 
51. Stone, E. A., L. S. Freedman and L. E. Morgano. Brain and adrenal tyrosine hydroxylase activity after chronic foot shock stress. Pharmacol Biochem Behav 9: 551-553, 1978.

52. Storlien, L. H. and D. J. Albert. The effect of VMH lesions, lateral cuts, and anterior cuts on food intake, activity level food motivation and reactivity to task. Physiol Behav 9: 191-196, 1972.

53. Thierry, A. M., G. Blanc and J. Glowinski. Effect of stress on disposition of catecholamines localized in various interneuronal storage forms in the brain stem of the rat. $J$ Neurochem 18: 449-461, 1971.

54. Wachtel, H., S. Ahlenius and N. E. Anden. Effects of locally applied dopamine to the nucleus accumbens on the motor activity of normal rat and following $\alpha$-methyltyrosine or reserpine. Psychopharmacology 63: 203-206, 1979.
55. Wade, G. N. Sex hormones, regulatory behaviors, and body weight. Adv Stud Behav 6: 201-279, 1976.

56. Weiss, T. M. W. H. Bailey, L. A. Pohorecky, D. Korzeniowski and G. Grillione, Stress induced depression of motor activity correlates with regional changes in brain norepinephrine but not dopamine. Neurochem Res 5: 9-22, 1980.

57. Widmaier, E. P. and C. S. Campbell. Interaction of estradiol and photoperiod on activity patterns in the female hamster. Physiol Behav 24: 923-930, 1980.

58. Yen, T. T. T. and J. M. Acton. Locomotor activity of various types of genetically obese mice. Proc Soc Exp Biol Med 140: $647-650,1972$. 